\title{
Nasal peak inspiratory flow at altitude
}

\author{
P.W. Barry*, N.P. Mason", J-P. Richalet
}

Nasal peak inspiratory flow at altitude. P.W. Barry, N.P. Mason, J-P. Richalet. (C) ERS Journals Ltd 2002.

ABSTRACT: The present study investigated whether there are changes in nasal peak inspiratory flow (NPIF) during hypobaric hypoxia under controlled environmental conditions.

During operation Everest III (COMEX '97), eight subjects ascended to a simulated altitude of $8,848 \mathrm{~m}$ in a hypobaric chamber. NPIF was recorded at simulated altitudes of $0 \mathrm{~m}, 5,000 \mathrm{~m}$ and $8,000 \mathrm{~m}$. Oral peak inspiratory and expiratory flow (OPIF, OPEF) were also measured. Ambient air temperature and humidity were controlled.

NPIF increased by a mean \pm SD of $16 \pm 12 \%$ from sea level to $8,000 \mathrm{~m}$, whereas OPIF increased by $47 \pm 14 \%$. NPIF rose by $0.085 \pm 0.03 \mathrm{~L} \cdot \mathrm{s}^{-1}$ per kilometre of ascent $(p<0.05)$, significantly less than the rise in OPIF and OPEF of $0.35 \pm 0.10$ and $0.33 \pm 0.04 \mathrm{~L} \cdot \mathrm{s}^{-1}$ per kilometre $(\mathrm{p}<0.0005)$.

Nasal peak inspiratory flow rises with ascent to altitude. The rise in nasal peak inspiratory flow with altitude was far less than oral peak inspiratory flow and less than the predicted rise according to changes in air density. This suggests flow limitation at the nose, and occurs under controlled environmental conditions, refuting the hypothesis that nasal blockage at altitude is due to the inhalation of cold, dry air. Further work is needed to determine if nasal blockage limits activity at altitude.

Eur Respir J 2002; 19: 16-19.
* Dept of Child Health, University of Leicester, Leicester, UK, ${ }^{\#}$ Université Libre de Bruxelles, Laboratoire de Physiologie et de Physiopathologie, Faculté de Médecine - Campus Erasme, Bruxelles, Belgium, "Association pour la Recherche en Physiologie de 1'Environnement, Laboratoire de Physiologie, UFR de Médecine, France.

Correspondence: P.W. Barry, Dept of Child Health, University of Leicester, Clinical Sciences Building, Leicester Royal Infirmary, PO Box 65, Leicester, LE2 7LX, UK.

Fax: 01162523282

Keywords: Altitude, nasal obstruction, spirometry

Received: November 112000

Accepted after revision July 252001

This study was supported by grants from the Région Provence-Alpes-Côte $\mathrm{d}^{\prime}$ Azur and the Ministère de la Jeunesse et des Sports (France).
The upper respiratory tract conditions inspired air, and recovers heat and water during expiration [1]. At high altitude, a large amount of air needs to be conditioned due to the increase in respiratory minute volume associated with exposure to hypobaric hypoxia [2]. Athletes and climbers at high altitude are particularly vulnerable to heat and water losses due to the severe environmental conditions often experienced. There have been a number of anecdotal reports of nasal mucosal damage in mountaineers and climbers $[3,4]$, and an increase in subjective feelings of nasal blockage and impairment of nasal muco-ciliary function on ascent to altitude has been demonstrated [5]. To objectively measure changes in nasal function at altitude, the present authors undertook a study to measure the changes in nasal peak inspiratory flow (NPIF) during hypobaric hypoxia under controlled environmental conditions.

\section{Methods}

The study took place over six weeks in a hypobaric chamber located at COMEX Industries, Marseille, France. Eight subjects were selected from healthy

$\overline{\text { For editorial comments see page } 4 .}$ male volunteers after physical and psychological assessment. All subjects had previous mountaineering exposure to high altitude. Subject demographics are given in table 1 . None were taking regular medication or had a history of atopy, nasal surgery, trauma or recent upper respiratory tract infection. The selection of subjects, their ascent profile and the general schedule have been detailed elsewhere [6].

To minimize the time spent confined in the hypobaric chamber, after baseline tests at sea level, the subjects ascended to the Vallot Observatory on Mont Blanc at $4,350 \mathrm{~m}$ for a five day period of acclimatization, spending the first night en route at the Cosmiques Hut $(3,613 \mathrm{~m})$. Subjects then returned to Marseille where they spent a night before re-entering the chamber, which was immediately depressurized to an altitude of $4,500 \mathrm{~m}$. Over the next 31 days, the subjects ascended to the barometric equivalent of the summit of Mount Everest (altitude 8,848 m, barometric pressure $253 \mathrm{mmHg}$ ). A period of recovery at $5,000 \mathrm{~m}$ was included prior to exposure to altitudes of $8,000 \mathrm{~m}$ and above, as would normally be adopted during a real mountaineering ascent to such altitudes. Temperature and relative humidity in the chamber varied during the day, and with changes in the chamber pressure, but were maintained between $18-24{ }^{\circ} \mathrm{C}$ and $30-60 \%$ respectively. Air in the chamber 
Table 1. - Subject biometrics

\begin{tabular}{lccccc}
\hline Subject & Age yrs & Height $\mathrm{m}$ & Weight $\mathrm{kg}$ & Smoker cigs·day $^{-1}$ & Maximum previous altitude $\mathrm{m}$ \\
\hline 1 & 23 & 1.80 & 65 & 2 & 4807 \\
2 & 37 & 1.83 & 75.5 & no & 8760 \\
3 & 25 & 1.90 & 81 & no & $>6000$ \\
4 & 25 & 1.89 & 82 & no & $>6000$ \\
5 & 26 & 1.76 & 72.5 & 4 & 76000 \\
6 & 25 & 1.77 & 70 & no & 5200 \\
7 & 25 & 1.72 & 66 & no & 4100 \\
8 & 26 & 1.76 & 78 & & \\
\hline
\end{tabular}

was filtered of atmospheric pollutants. The study was approved by the ethics committee of the University of Marseille. All subjects gave their written informed consent.

NPIF was measured at sea level and at barometric pressures equivalent to $5,000 \mathrm{~m}$ and $8,000 \mathrm{~m}$ using a modified fixed orifice Micro Medical Microplus hand-held turbine spirometer (Micro Medical Ltd., Rochester, UK) fitted with a nasal continuous positive airway pressure mask. Subjects placed the spirometer to the nose, ensuring a close seal, and then inhaled as forcibly as possible through the nose from residual volume. The greatest inspiratory flow of three inspirations was recorded. Oral flow volume loops were also recorded using a Micromedical Microloop turbine spirometer. Turbine spirometers such as these have been validated for use at low barometric pressures [7]. Each day arterial oxygen saturation was recorded using a pulse oximeter (Hewlett Packard, Palo Alto, CA, USA).

A number of flow measurements are missing. Subject 1 developed severe headache and focal neurological signs at an altitude of $8,000 \mathrm{~m}$ and his data at this altitude is therefore not available. Oral spirometry data is not available from subject 6 at 5,000 $\mathrm{m}$ due to technical problems with the spirometer.

The overall effect of altitude on peak flow was determined by linear modelling [8]. The model allows multiple factors, such as differences between subjects, to be analysed to explain the observed changes in spirometry. Peak flows at different altitudes were then compared by a paired t-test. Data was analysed using Minitab Release 10 (Clecom Ltd., Birmingham, UK). Statistical significance was assumed at $\mathrm{p}<0.05$.

\section{Results}

The results are presented in table 2. NPIF increased by a mean (95\% confidence interval (CI)) of $16 \%$ $(7-25 \%)$ from sea level to $8,000 \mathrm{~m}(\mathrm{p}=0.021)$, whereas oral peak inspiratory flow (OPIF) increased by $47 \%$ $(95 \%$ CI 36-58\%, $\mathrm{p}=0.001)$, and oral peak expiratory flow (OPEF) by 31\% (95\% CI 24-38\%, p $<0.001)$ (fig. 1). The changes in OPEF are in keeping with previous reports [9, 10]. Linear modelling, used to take account of intersubject variation, demonstrated a rise in NPIF of $0.086 \pm 0.03 \mathrm{~L} \cdot \mathrm{s}^{-1}$ per kilometre of

Table 2. - Spirometric results and oxygen saturation at different simulated altitudes

\begin{tabular}{|c|c|c|c|c|c|}
\hline Altitude m & Subject & NPIF $L \cdot s^{-1}$ & OPIF $L \cdot s^{-1}$ & OPEF $L \cdot s^{-1}$ & Oxygen saturation $\%$ \\
\hline \multirow[t]{7}{*}{0} & 1 & 198 & 378 & 624 & 99 \\
\hline & 2 & 198 & 264 & 492 & 99 \\
\hline & 3 & 192 & 510 & 534 & 98 \\
\hline & 4 & 372 & 720 & 720 & 98 \\
\hline & 5 & 228 & 426 & 522 & 99 \\
\hline & 7 & 204 & 534 & 780 & 98 \\
\hline & 8 & 198 & 348 & 540 & 98 \\
\hline \multirow[t]{7}{*}{5000} & 1 & 252 & 336 & 732 & 84 \\
\hline & 2 & 228 & 552 & 672 & 86 \\
\hline & 3 & 240 & 600 & 618 & 87 \\
\hline & 4 & 426 & 690 & 870 & 84 \\
\hline & 5 & 270 & 612 & 642 & 85 \\
\hline & 7 & 252 & 612 & 840 & 84 \\
\hline & 8 & 318 & 564 & 690 & 82 \\
\hline \multirow[t]{7}{*}{8000} & 1 & ND & ND & ND & ND \\
\hline & 2 & 240 & 414 & 690 & 80 \\
\hline & 3 & 198 & 780 & 726 & 70 \\
\hline & 4 & 378 & 882 & 882 & 67 \\
\hline & 5 & 252 & 684 & 714 & 69 \\
\hline & 7 & 258 & 636 & 912 & 57 \\
\hline & 8 & 252 & 504 & 744 & 66 \\
\hline
\end{tabular}

NPIF: nasal peak inspiratory flow; OPIF: oral peak inspiratory flow; OPEF: oral peak expiratory flow; ND: not determined. 


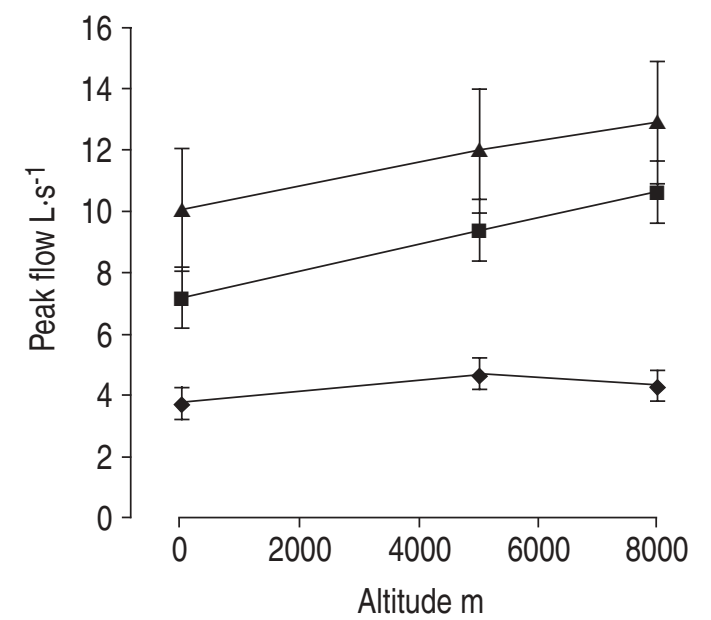

Fig. 1.- Nasal peak inspiratory flow $(\bullet)$, oral peak inspiratory flow $(\boldsymbol{\square})$ and oral peak expiratory flow $(\boldsymbol{\Delta})$ at different simulated altitudes.

ascent $(\mathrm{p}<0.001)$, compared to a greater rise in OPIF and OPEF of $0.4 \pm 0.08$ and $0.38 \pm 0.03 \mathrm{~L} \cdot \mathrm{s}^{-1}$ per kilometre of ascent ( $\mathrm{p}<0.001$ for both).

\section{Discussion}

NPIF increases during hypobaric hypoxia, but this increase is less than that seen in OPIF and OPEF, suggesting an increase in airflow limitation in the nose at altitude. The present authors' previous study [5] demonstrated an increase in subjective feelings of nasal blockage (and a decrease in nasal mucociliary transport) in subjects ascending to $5,300 \mathrm{~m}$. This is the first report of an objective measure of nasal air-flow at altitude. The present authors have not determined the mechanisms for this finding, or its importance to performance at altitude.

Cockroft et al. [11] demonstrated a $48 \%$ increase in NPIF in subjects breathing $80 \%$ helium with $20 \%$ oxygen, which has a density $\sim 36 \%$ that of air. Increases in peak inspiratory and expiratory flows during hypobaria may also be due to changes in gas density. If so, the predicted increase in flow will be inversely proportional to the square root of the gas density ratio, and this can be calculated directly from the change in barometric pressure [12]. Thus the predicted increase at $8,000 \mathrm{~m}$ (barometric pressure $37.4 \mathrm{kPa}$, and a sea level barometric pressure $100.1 \mathrm{kPa}$ ) is $64 \%$. In this study, NPIF rose by only $16 \%$, from a mean of $3.8 \mathrm{~L} \cdot \mathrm{s}^{-1}$ at sea level to $4.2 \mathrm{~L} \cdot \mathrm{s}^{-1}$ at $8,000 \mathrm{~m}$. Most of the rise was seen between sea level and $5,000 \mathrm{~m}$, with a small, statistically insignificant, fall in NPIF between $5,000 \mathrm{~m}$ and $8,000 \mathrm{~m}$ (fig. 1). Increases in OPIF and OPEF were greater than NPIF, but not as large as those predicted by changes in air density. Possible mechanisms for this discrepancy have been discussed elsewhere [10]. These include increased viscosity-dependent frictional losses in the airways, failure to reach wave speed, reduced muscle power, reduced total lung capacity or reduced elastic recoil between the calculated and observed increase in peak expiratory flows. Subject motivation may also have been reduced in the latter part of the study, reducing inspiratory and expiratory effort, although all subjects remained ostensibly well motivated and keen to undertake their tasks throughout the study.

The difference between the increase in nasal and oral peak inspiratory flow may be explained by an increase in nasal blockage. Inspiration of large volumes of air causes congestion of erectile tissue in the nose, to facilitate heat exchange with inspired and expired air [13], and increases nasal secretion, leading to nasal blockage [14, 15]. The present authors previously postulated that the increase in subjective feelings of nasal blockage were due to the inhalation of cold dry air at altitude. The experiments described in this paper were undertaken under controlled environmental conditions, and do not support the hypothesis that nasal blockage at altitude is due to the inhalation of cold dry air. In controlled environments, others have shown changes in mucociliary transport only with very cold [16] or very dry [17] air. However, none of these studies has included the increase in minute ventilation which accompanies exposure to high altitude. The results of the present study are consistent with changes in nasal patency being due to the inhalation of large volumes of air that are inspired and conditioned in the nose. Exercise at altitude is accompanied by even higher levels of minute ventilation [2], and although nasal resistance normally falls during exercise [18], it is not known if nasal blockage affects maximum work rates and performance at altitude. Partial nasal blockage increases the work of breathing at sea level [19], and encourages oral or oronasal breathing. Mountaineers have often reported sore noses and throats occurring at altitude, limiting their ability to climb [3, 4]. Aids are available to facilitate nasal opening [20], but these have not been evaluated at altitude.

Acute Mountain Sickness is characterised by peripheral oedema and it is possible that decreased nasal flow is due to swelling of the nasal structures obstructing the airway. There is some evidence that most subjects exposed to high altitude develop a degree of subclinical pulmonary oedema [21, 22], and this has been suggested as the cause of changes in lung function seen at altitude [23]. There is, however, no work on the presence of oedema in the nose at altitude.

Measurement of NPIF has been shown to be a reproducible and valid measurement compared to other measures of nasal airflow, such as rhinomanometry, nasal peak expiratory flow or subjective measures of nasal patency [24-29]. The advantage of using NPIF is that the equipment is relatively inexpensive and portable, the measurement is rapid, noninvasive and easy for the subject to perform.

In conclusion, nasal peak inspiratory flow rises with ascent to altitude, but less than oral peak flow measurements, suggesting flow limitation at the nose. This is consistent with previous reports of subjective nasal blockage at altitude, and further work is needed to determine if this limits the activity of climbers and athletes at altitude. 
Acknowledgements. The authors gratefully acknowledge the participation of the subjects and the staff of COMEX, without whose dedication and cooperation the study would not have been possible.

\section{References}

1. Cole P. Modification of inspired air. In: Proctor DF, Andersen I, eds. The nose: Upper airway physiology and the atmospheric environment. Amsterdam, Elsevier Biomedical Press, 1982; pp. 351-375.

2. Ward MP, Milledge JS, West JB. High Altitude Medicine and Physiology. 2nd Edn. London, Chapman \& Hall, 1995; pp. 221-225.

3. Somervell TH. After Everest. London, Hodder and Stoughton, 1936.

4. Unsworth H. Everest. 2nd Edn. London, Grafton, 1991.

5. Barry PW, Mason NP, O'Callaghan C. Nasal mucociliary ransport is impaired at altitude. Eur Respir $J$ 1997; 10: 35-37.

6. Richalet J-P, Robach P, Jarrot S, et al. Operation Everest III (COMEX '97). In: Roach RC, Wagner PD, Hackett PH, eds. Hypoxia: Into the Next Millennium. New York, Plenum/Kluwer Academic Publishing, 1999; pp. 297-317.

7. Pedersen OF, Miller MR, Sigsgaard T, Tidley M, Harding RM. Portable peak flow meters: physical characteristics, influence of temperature, altitude, and humidity. Eur Respir J 1994; 7: 991-997.

8. Altman DG. Practical statistics for medical research. London, Chapman and Hall, 1991; pp. 344-345.

9. Pollard AJ, Mason NP, Barry PW, et al. Effect of altitude on spirometric parameters and the performance of peak flow meters. Thorax 1996; 51: 175-178.

10. Mason NP, Barry PW, Richalet JP. Cough frequency and cough receptor sensitivity to citric acid challenge during a simulated ascent to extreme altitude. Eur Respir J 1999; 13: 508-513.

11. Cockcroft DW, Hargreave FE, Pengelly LD. The effect of helium on nasal resistance and nasal flows. Am Rev Resp Dis 1979; 120: 607-699.

12. Dawson SV, Elliot EA. Wave-speed limitation on expiratory flow - a unifying concept. J Appl Physiol 1977; 43: 498-415.

13. Maran AGD, Lund VJ. Clinical Rhinology. New York, Theime Medical Publishers, 1990.

14. Philip G, Jankowski R, Baroody FM, Naclerio RM, Togias AG. Reflex activation of nasal secretion by unilateral inhalation of cold dry air. Am Rev Respir Dis 1993; 48: 1616-1622.
15. Silvers WS. The skiers nose. Ann Allergy 1991; 67: 3236.

16. Proctor DF, Anderson IB, Lundqvist GR. Human nasal mucosal function at controlled temperatures. Respir Physiol 1977; 30: 109-124.

17. Salah B, Dinh Xuan AT, Fouilladieu JL, Lockhart A, Regnard J. Nasal mucociliary transport in healthy subjects is slower when breathing dry air. Eur Respir $J$ 1988; 1: 852-855.

18. Olson LG, Strohl KP. The response of the nasal airway to exercise. Am Rev Respir Dis 1987; 135: 356359

19. Cole P, Niinimaa V, Mintz S, Silverman F. Work of nasal breathing: Measurement of each nostril independently using a split mask. Acta Otolaryngol 1979; 88: $148-154$

20. Vermoen CJ, Verbraak AFM, Bogaard JM. Effect of a nasal dilator on nasal patency during normal and forced nasal breathing. Int J Sports Med 1998; 19: 109-113.

21. Gray GW, McFadden MD, Houston CS, Bryan AC. Changes in the single-breath nitrogen washout curve on exposure to 17,600 ft. $J$ Appl Physiol 1975; 39: 652656.

22. Welsh CH, Wagner PD, Reeves JT, et al. Operation Everest II: Spirometric and radiographic changes in acclimatised humans at simulated high altitudes. Am Rev Respir Dis 1993; 147: 1239-1244.

23. Mason NP, Barry PW, Pollard AJ, et al. Serial changes in spirometry during an ascent to $5300 \mathrm{~m}$ in the Nepalese Himalayas. High Alt Med Biol 2000; 1: 185-196.

24. Cho S-I, Hanser R, Christiani DC. Reproducibility of nasal peak inspiratory flow among healthy adults. Chest 1997; 112: 1547-1553.

25. Fairley JW, Durham LH, Ell SR. Correlation of subjective sensation of nasal patency with nasal peak inspiratory flow rate. Clin Otolaryngol 1993; 18: 19-22.

26. Gleeson MJ, Youlten LJ. Shelton DM. Siodlak MZ. Eiser NM. Wengraf CL. Assessment of nasal airway patency, a comparison of four methods. Clin Otolaryngol 1986; 11: 99-107.

27. Holmstrom M, Scadding GK, Lund VJ, Darby YC. Assessment of nasal obstruction: a comparison of rhinomanometry and nasal inspiratory peak flow. Rhinology 1990; 28: 191-196.

28. Jones AS, Viani L, Phillips D, Charters P. The objective assessment of nasal patency. Clin Otolaryngol 1991; 16: 206-211.

29. Wihl JA, Malm L. Rhinomanometry and nasal peak expiratory and inspiratory flow rate. Ann Allergy 1988; 61: 50-55. 